\title{
PERSONAL LOAN SALES FORECASTING THROUGH TIME SERIES ANALYSIS
}

\section{Ali İhsan ÖZEROĞLU}

Istanbul Rumeli University, Faculty of Economics, Administrative and Social Sciences, aihsan.ozer@ rumeli.edu.tr

\author{
Article history: \\ Submission 14 December 2020 \\ Revision 26 February 2021 \\ Accepted 27 March 2021 \\ Available online 30 April 2021
}

\section{Keywords:}

Time Series,

Sales,

Correlogram.

DOI:

https://doi.org/10.32936/pssj.v5i1.216

\begin{abstract}
A b s t r a t
Almost all state enterprises and private sector companies try to foresee future expectations. From the viewpoint of economic, productive, and efficient business management, this is highly important. By making rational decisions, all enterprises aim to rich maximum profitability by taking sales, cost, human resource needs, profits into account. For this reason, enterprises have to make reliable and reasonable forecasts to take the right decisions.
\end{abstract}

Such forecasts might be used in budgeting, cost, and profit analysis. Forecasted scenarios might come true in the future with a great likelihood. The researcher utilizing time series analysis assumes that all findings that come out will be almost the same happened in the past.

Analyzing the time series consist of four aims such as defining, modeling forecasting, and controlling. To define a series, it is needed to compute definitional statistics and to draw its graphic. The second purpose of analyzing the time series is to find the appropriate model of the time series. With that work called "Time series and application to sale data", it is tried to make a suitable guess model by analyzing the data of personal loans of a bank 2004-2010 sale data based on unit. During the stagnation stage of the sequence correlogram and root, analyses are performed. The sequence is analyzed with the help of the Eviews 5,1 program. At the end of the survey, it is seen that natural logarithmic personal loan sale sequences are at their level and in the first gap it is not constant and it is also seen that when the second gap is taken, the constant is obtained. The sequence of which the second gap is taken is shown based on time-way graphs and correlogram. When the constant is provided, the guessed model is formed by taking the second gap. The suitability of the model is observed by the correlogram, Akaike information criteria (AIC), and Schwarz information criteria (SIC) merits.

\section{Introduction}

\subsection{Bank and personal loan sales}

In addition to marketing components, statistical and econometric applications are the guiding concepts in the execution of marketing/sales activities of banks. Every business established produces a tangible or intangible product, determines its price, plans its sales to potential buyers and makes sales forecasts, regardless of its purpose. When these estimates are based on the statistical and econometric model as in this study, banks take the most rational activity to ensure optimum profitability by getting rid of unnecessary operational costs in personal loan sales.
After the banks make market segmentation in the current market to sell personal loans, they move to the target market selection stage. They should be sure that they will be able to respond to the demands and needs of the target market they will choose with the products and services they produce, and it must be a market where it will provide profitable and appropriate services for the bank.

People's perceptions, attitudes, and behaviors, wants, and needs differ within the market. This is proof that the market is in a heterogeneous structure. However, a bank cannot serve the whole market in a heterogeneous structure where people have different 
purchasing thoughts in terms of personal loan sales. For this reason, it separates the markets with the same kind of attitude and chooses the market to serve by determining the demands and needs of each market. For this purpose, they can make predictions for the next year using the past year's data. Acting in this way, the bank divides the market by making the market homogeneous.

\subsection{Application Series}

The data set used in the program shows the total monthly personal loan sales of BETA BANK INC. between 2004-2010. (Unit)

\subsection{Purpose of Application}

This study aims to analyze the stagnation by using the total personal loan series between 2004-2010 and to estimate the appropriate model as a result of the stationary analysis.

\subsection{Method Used in Practice}

Series stationary analysis; was performed with the correlogram test and unit root tests, which are the most widely used in the literature. The serial was analyzed with the help of the Eviews 5.1 program. The data set used is given in Table 1.

Table 1. Time Series Application Data

\begin{tabular}{|l|l|l|l|l|l|l|l|}
\hline & $\mathbf{2 0 0 4}$ & $\mathbf{2 0 0 5}$ & $\mathbf{2 0 0 6}$ & $\mathbf{2 0 0 7}$ & $\mathbf{2 0 0 8}$ & $\mathbf{2 0 0 9}$ & $\mathbf{2 0 1 0}$ \\
\hline January & 8.550 & 10.344 & 14.106 & 17.953 & 23.397 & 26.357 \\
\hline February & 8.642 & 10.580 & 14.457 & 16.995 & 22.629 & 23.257 \\
\hline March & 9.468 & 12.790 & 16.314 & 20.368 & 24.539 & 24.195 \\
\hline Engagement & 9.465 & 13.244 & 14.785 & 18.785 & 24.918 & 24.894 & 27.583 \\
\hline May & 9.955 & 13.790 & 17.146 & 23.369 & 26.302 & 26.830 & 28.546 \\
\hline June & 11.769 & 14.740 & 19.201 & 26.760 & 31.976 & 31.903 & 32.879 \\
\hline July & 12.992 & 17.289 & 20.559 & 30.969 & 38.011 & 34.763 & 35.292 \\
\hline August & 13.402 & 20.095 & 24.482 & 33.061 & 37.433 & 31.328 & 37.874 \\
\hline September & 12.177 & 17.029 & 18.435 & 25.807 & 31.893 & 26.727 & 29.878 \\
\hline October & 11.647 & 15.015 & 16.937 & 25.360 & 28.473 & 27.269 & 27.000 \\
\hline November & 10.102 & 14.600 & 17.660 & 23.327 & 25.251 & 22.763 & 24.294 \\
\hline December & 11.631 & 15.672 & 17.433 & 21.779 & 25.570 & 25.555 & 27.457 \\
\hline
\end{tabular}

The view of the personal loan sales data for the original data set was given in Figure 1.

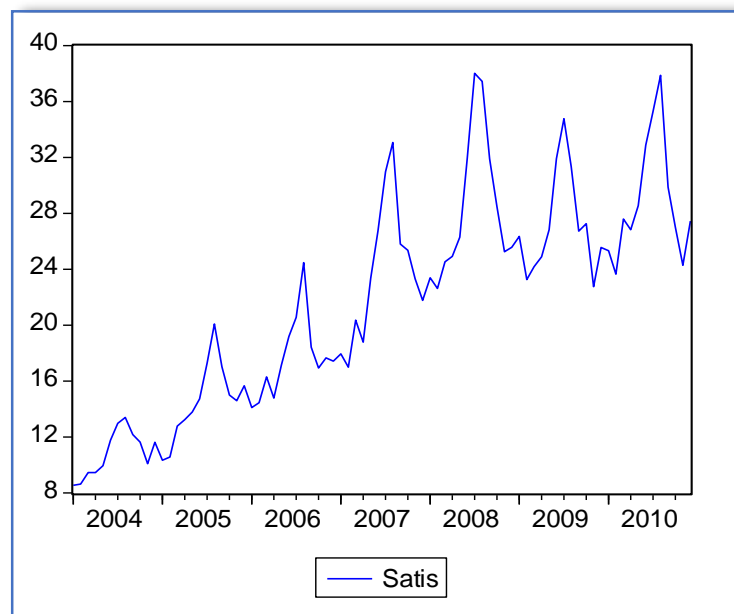

Figure 1. Time Path Chart of Personal Loan Sales Series

As can be seen from Figure 1, a linear increasing trend has been observed in the data set. To protect against possible changing variance and autocorrelation, the natural logarithm of the series was taken and the analysis continued over the new logarithmic series. The time-dependent view of the new series defined as LSATIS (LSALES) was given in Figure 2.

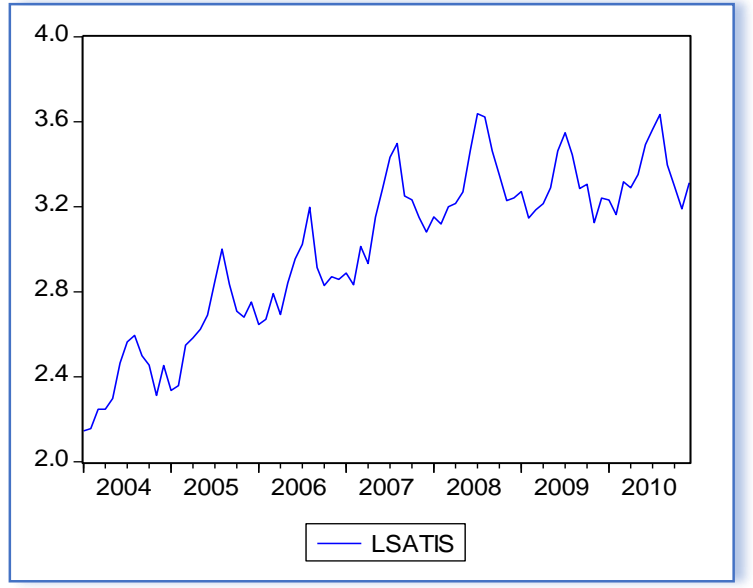

Figure 2. Time Path Graph of Personal Loan Sales Series with Natural Logarithms

When the time path graph of the LSATIS (LSALES) data consisting of 84 observations was examined, it was seen that the data were not distributed around a certain average, contain a linear increasing trend and therefore not stationary. 


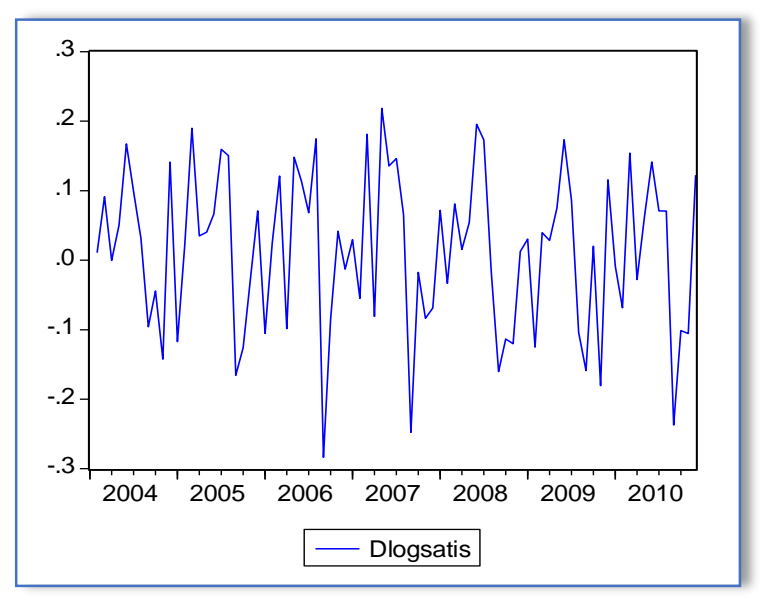

Figure 3. Time Path Graph of LSATIS (LSALES) Data with First Difference

The time path graph obtained by taking the first difference of nonstationary logarithmic personal loan sales data was given in Figure 3. It was observed that the series obtained by using the first difference operator became more stable, but there was weak stationarity in the series. The stationarity was tried to be observed graphically by using the second difference operator.

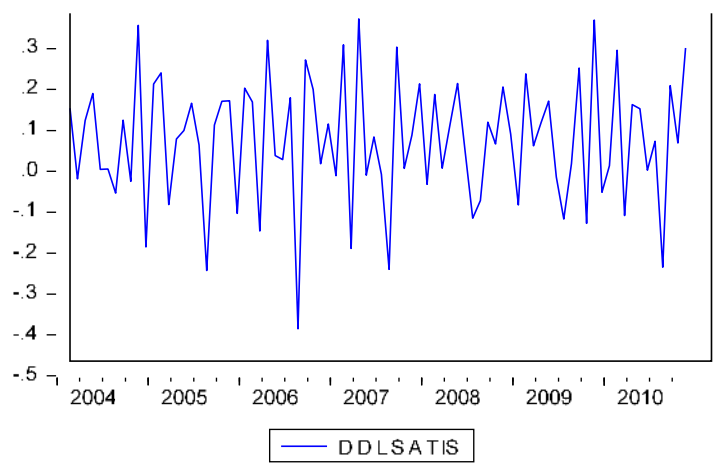

Figure 4. Time Path Graph of LSATIS (LSALES) Data with

\section{Second Difference}

The time path graph of the logarithmic personal loan sales data of which the second difference is taken is given in Figure 4. Accordingly, it was observed on the graph that the stationarity was obtained in the second difference.

\begin{tabular}{|c|c|c|c|c|c|c|c|c|}
\hline \multicolumn{2}{|c|}{ Autocorrelation } & \multicolumn{2}{|c|}{ Partial Correlation } & & $A C$ & PAC & Q-Stat & Prob \\
\hline it & & it & 5 & 1 & 0.919 & 0.919 & 73.530 & 0.000 \\
\hline 1 & 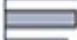 & id & 1 & 2 & 0.830 & .0 .098 & 134.15 & 0.000 \\
\hline 1 & 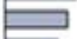 & 10 & 1 & 3 & 0.729 & -0.116 & 181.58 & 0.000 \\
\hline 1 & $\square$ & $1]$ & 1 & 4 & 0.638 & 0.007 & 218.32 & 0.000 \\
\hline 1 & $\square$ & 1 & ים & 5 & 0.573 & 0.121 & 248.39 & 0.000 \\
\hline 1 & $\square$ & 10 & 1 & 6 & 0.532 & 0.085 & 27459 & 0.000 \\
\hline 1 & $\square$ & 11 & إ & 7 & 0.520 & 0.134 & 299.97 & 0.000 \\
\hline 1 & $\square$ & 11 & 1 & 8 & 0.515 & 0.014 & 325.17 & 0.000 \\
\hline 1 & $\square$ & 11 & 1 & 9 & 0.508 & -0.011 & 350.06 & 0.000 \\
\hline if & 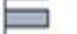 & 1 & 1 & 10 & 0.507 & 0.072 & 375.12 & 0.000 \\
\hline 1 & 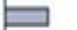 & 18 & 11 & 11 & 0.503 & 0.050 & 400.15 & 0.000 \\
\hline 1 & $\square$ & 11 & 1 & 12 & 0.489 & -0.026 & 424.15 & 0.000 \\
\hline 1 & $\Xi$ & c & 1 & 13 & 0.417 & -0.374 & 441.81 & 0.000 \\
\hline 1 & $\Xi$ & id & 1 & 14 & 0.336 & -0.059 & 453.46 & 0.000 \\
\hline 1 & 曰 & 11 & 1 & 15 & 0.250 & -0.017 & 460.00 & 0.000 \\
\hline 1 & 曰 & 1 & 1 & 16 & 0.182 & 0.079 & 463.53 & 0.000 \\
\hline 1 & 91 & 1 & 1 & 17 & 0.137 & 0.001 & 465.54 & 0.000 \\
\hline 1 & 21 & c & 1 & 18 & 0.094 & -0.173 & 466.52 & 0.000 \\
\hline 1 & 1 & 1 & 1 & 19 & 0.086 & 0.072 & 467.34 & 0.000 \\
\hline 1 & 21 & 1 & 1 & 20 & 0.089 & 0.109 & 468.24 & 0.000 \\
\hline 1 & 11 & 10 & 1 & 21 & 0.076 & 0.092 & 468.89 & 0.000 \\
\hline 1 & 1 & 1) & 1 & 22 & 0.075 & 0.056 & 469.55 & 0.000 \\
\hline 1 & 11 & 1 & 1 & 23 & 0.073 & 0.016 & 470.19 & 0.000 \\
\hline 1 & 21 & 1 & 1 & 24 & 0.068 & 0.010 & 470.75 & 0.000 \\
\hline 1 & 11 & id & 1 & 25 & 0.033 & -0.047 & 470.88 & 0.000 \\
\hline 11 & 1 & $1]$ & 1 & 26 & -0.010 & .0 .004 & 470.89 & 0.000 \\
\hline 18 & 1 & 1 & 1 & 27 & 0.054 & 0.021 & 471.26 & 0.000 \\
\hline 10 & 1 & 11 & 1 & 28 & -0.092 & 0.038 & 472.35 & 0.000 \\
\hline 10 & 1 & 1 & P & 29 & 0.098 & 0.161 & 473.62 & 0.000 \\
\hline 10 & 1 & 10 & 11 & 30 & 0.090 & 0.081 & 474.71 & 0.000 \\
\hline 10 & 1 & 드 & 1 & 31. & -0.077 & -0.184 & 475.52 & 0.000 \\
\hline 18 & 1 & 1 & 1 & 32 & 0.057 & 0.002 & 475.97 & 0.000 \\
\hline 10 & 1 & Id & 1 & 33 & -0.061 & -0.063 & 476.50 & 0.000 \\
\hline 10 & 1 & 1 & 1 & 34 & -0.060 & 0.076 & 477.02 & 0.000 \\
\hline id & 1 & 1 & 61 & 35 & 0.061 & 0.062 & 477.56 & 0.000 \\
\hline 10 & 1 & 10 & 1 & 36 & 0.060 & .0 .082 & 478.11 & 0.000 \\
\hline
\end{tabular}

Figure 5. Correlogram of Personal Loan Sales Series with Logarithms (LSATIS (LSALES))

The correlogram graph regarding the errors of the logarithmic personal loan sales data was given in Figure 5. Vertical lines in Figure 8 show the $95 \%$ acceptance region. As it is seen from the correlogram, it was concluded that there was a significant autocorrelation and partial autocorrelation since the calculated $\mathrm{ACF}(\mathrm{k})$ and PACF $(\mathrm{k})$ for $\mathrm{k}=36$ lags were out of the confidence interval. Again, it was concluded from Figure 5 that the series was not stationary.

The correlogram of the logarithmic personal loan sales data, the values of the autocorrelation function calculated over 36 selected delay periods were given in the column indicated by AC. Since the series was not distributed around a certain mean, the correlogram of the autocorrelation function started from a high value and gradually decreased, which suggests that the series was not stationary.

\subsection{Unit Root Test for LSATIS (LSALES) Series}

A unit root test at its own level was performed on logarithmic personal loan sales data and the results are given in Table 2 . 
Table 2. Self-Level Unit Root Test Results of LSATIS (LSALES) Data

\begin{tabular}{llll} 
& & t-Statistic & Prob.* \\
\hline \hline Augmented Dickey-Fuller test statistic & & 0.830865 & 0.8888 \\
\hline Test critical values: & $1 \%$ level & -2.593121 & \\
& $5 \%$ level & -1.944762 & \\
& $10 \%$ level & -1.614204 & \\
\hline \hline
\end{tabular}

*MacKinnon (1996) one-sided p-values.

\begin{tabular}{lclll} 
Variable & Coefficient & Std. Error & t-Statistic & Prob. \\
\hline \hline LOGSATIS(-1) & 0.003474 & 0.004181 & 0.830865 & 0.4085 \\
\hline \hline R-squared & -0.006704 & Mean dependent var & 0.014057 \\
Adjusted R-squared & -0.006704 & S.D. dependent var & 0.114784 \\
S.E. of regression & 0.115168 & Akaike info criterion & -1.472875 \\
Sum squared resid & 1.087620 & Schwarz criterion & -1.443732 \\
Log likelihood & 62.12431 & Durbin-Watson stat & 1.809179
\end{tabular}

From Table 2, since the significance levels of the $\tau$ statistic $1 \%$, $5 \%, \quad 10 \% \quad(-2.593121 ;-1.944762 ;-1.614204)$ given by MacKinnon were higher than the calculated $\tau(0.830865)$ value in absolute value, it has been observed that LSATIS series had unit root, that is, the series was not stationary. In this case, the unit root test was applied again by taking the first difference of the series.

Table 3. First Difference (DLSATIS) (DLSALES) Unit Root Test Results of LSATIS (LSALES) Data

\begin{tabular}{llcc} 
& & t-Statistic & Prob.* \\
Augmented Dickey-Fuller test statistic & -1.335568 & 0.1667 \\
\hline Test critical values: & $1 \%$ level & -2.597939 & \\
& $5 \%$ level & -1.945456 & \\
& $10 \%$ level & -1.613799 & \\
\hline \hline
\end{tabular}

*MacKinnon (1996) one-sided p-values.

\begin{tabular}{lllll} 
Variable & Coefficient & Std. Error & t-Statistic & Prob. \\
\hline \hline D(LOGSATIS(-1) & -0.634433 & 0.475029 & -1.335568 & 0.1868 \\
D(LOGSATIS(-1),2) & -0.439535 & 0.444558 & -0.988703 & 0.3268 \\
D(LOGSATIS(-2),2) & -0.488335 & 0.408051 & -1.196749 & 0.2362 \\
D(LOGSATIS(-3),2) & -0.481089 & 0.370953 & -1.296898 & 0.1997 \\
D(LOGSATIS(-4),2) & -0.674317 & 0.334003 & -2.018896 & 0.0480 \\
D(LOGSATIS(-5),2) & -0.530905 & 0.295884 & -1.794298 & 0.0779 \\
D(LOGSATIS(-6),2) & -0.671860 & 0.258288 & -2.601209 & 0.0117 \\
D(LOGSATIS(-7),2) & -0.739761 & 0.226030 & -3.272842 & 0.0018 \\
D(LOGSATIS(-8),2) & -0.762656 & 0.185515 & -4.111021 & 0.0001 \\
D(LOGSATIS(-9),2) & -0.809909 & 0.155862 & -5.196324 & 0.0000 \\
D(LOGSATIS(-10),2) & -0.909432 & 0.121051 & -7.512812 & 0.0000 \\
D(LOGSATIS(-11),2) & -0.730020 & 0.088744 & -8.226178 & 0.0000 \\
\hline \hline
\end{tabular}




$\begin{array}{llll}\text { R-squared } & 0.827184 & \text { Mean dependent var } & 0.003375 \\ \text { Adjusted R-squared } & 0.794965 & \text { S.D. dependent var } & 0.157864 \\ \text { S.E. of regression } & 0.071482 & \text { Akaike info criterion } & -2.285853 \\ \text { Sum squared resid } & 0.301472 & \text { Schwarz criterion } & -1.903429 \\ \text { Log-likelihood } & 93.14779 & \text { Durbin-Watson stat } & 2.257636\end{array}$

In Table 3 , because the $\tau$ statistic given by MacKinnon is $1 \%, 5 \%$, $10 \%(-2.597939 ;-1.945456 ;-1.613799)$ significance levels were higher than the calculated $\tau(-1.335568)$ value as an absolute value, it was observed that the LSATIS (LSATIS) series whose first difference was taken had a unit root, that is, the series was not stationary. In this case, the second difference of the series was taken and the unit root test was applied again.

Table 4. Unit Root Test Results of DDLSATIS (DDLSALES) Data

\begin{tabular}{|c|c|c|c|c|}
\hline Augmented Dickey-Fuller test statistic & & & $\begin{array}{l}\text { t-Statistic } \\
-14.22155 \\
\end{array}$ & $\begin{array}{c}\text { Prob.* } \\
0.0000 \\
\end{array}$ \\
\hline Test critical values: & $1 \%$ level & & -2.597939 & \\
\hline & $5 \%$ level & & -1.945456 & \\
\hline & $10 \%$ level & & -1.613799 & \\
\hline Variable & Coefficient & Std. Error & t-Statistic & Prob. \\
\hline D(LOGSATIS(-1),1) & -11.71034 & 0.823423 & -14.22155 & 0.0000 \\
\hline D(LOGSATIS(-1),2) & 9.687131 & 0.773113 & 12.53004 & 0.0000 \\
\hline D(LOGSATIS(-2),2) & 8.667721 & 0.711467 & 12.18288 & 0.0000 \\
\hline D(LOGSATIS(-3),2) & 7.709863 & 0.638605 & 12.07298 & 0.0000 \\
\hline D(LOGSATIS(-4),2) & 6.610005 & 0.568707 & 11.62286 & 0.0000 \\
\hline D(LOGSATIS(-5),2) & 5.712785 & 0.484630 & 11.78794 & 0.0000 \\
\hline D(LOGSATIS(-6),2) & 4.724853 & 0.410929 & 11.49797 & 0.0000 \\
\hline D(LOGSATIS(-7),2) & 3.722863 & 0.320943 & 11.59977 & 0.0000 \\
\hline D(LOGSATIS(-8),2) & 2.752504 & 0.244375 & 11.26345 & 0.0000 \\
\hline D(LOGSATIS(-9),2) & 1.786992 & 0.159958 & 11.17164 & 0.0000 \\
\hline D(LOGSATIS(-10),2) & 0.775833 & 0.082379 & 9.417852 & 0.0000 \\
\hline R-squared & 0.938797 & Mean dependent var & & 0.006848 \\
\hline Adjusted R-squared & 0.928597 & S.D. dependent var & & 0.269250 \\
\hline S.E. of regression & 0.071947 & Akaike info criterion & & -1.284237 \\
\hline Sum squared resid & 0.310586 & Schwarz criterion & & -1.933681 \\
\hline Log-likelihood & 92.09043 & Durbin-Watson stat & & 1.308297 \\
\hline
\end{tabular}

In Table 4 , because the $\tau$ statistics given by MacKinnon is $1 \%$, $5 \%, 10 \%(-2.597939 ;-1.945456 ;-1.613799)$ significance levels were lower than the calculated absolute value of $\tau$ (-14.22155), it was observed that the LSATIS (DDLSATIS) series, whose second difference was taken, did not have a unit root, ie the series was stationary at the second difference.

\section{Box-Jenkins Method for Second Differential LSATIŞ (LSALES) Data}

\subsection{Stage 1. Determination}

It has been observed from the time path graphs and unit root tests that the logarithmic personal loan sales series were not stable at both their level and the first difference, but were stationary at the second difference. To investigate the AR and

MA status of the stationary I (2) LSATIS (LSALES) series, the correlogram of the LSATIS (LSALES) series in Figure 1 was 
looked at. The ACF graph in the correlogram shows that the autocorrelation values were gradually decreasing. This situation showed that the degree of MA in the model was zero, that is, it does not have a serial moving average. Looking at the PACF graph of the series, it was seen that the first lag value was high, it was only outside the $95 \%$ range for $\mathrm{k}=1$ in partial autocorrelation bars, and it gradually decreases in other lags. This situation indicates that the model had a typical autoregressive structure and the lag is $k=1$. So AR (1) is in question. Since the difference was taken twice to stabilize the personal loan sales series whose logarithms were taken, it was understood that the difference degree was $d=2$. Thus, it was decided that the series has the ARIMA $(1,2,0)$ structure.

\subsection{Step 2. Prediction}

At this stage, firstly, the parameter estimates of the determined model were made. After deciding the degrees of AR and MA in the model, the parameter values used in the model were calculated and the prediction model was created by writing these calculated values into the model. The created model is obtained as,

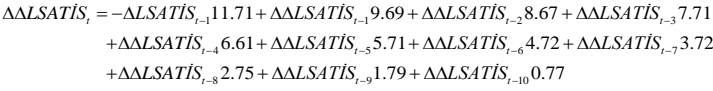

\subsection{Step 3. Compliance Testing}

After the prediction model has been created, the residuals of the model must be tested. If the residuals show the white noise feature (having a fixed mean and variance), the suitability of the fitted model is decided. For this, the correlogram of the error terms is examined. The relevant correlogram is given in Figure 2

\begin{tabular}{|c|c|c|c|c|c|c|c|c|}
\hline \multicolumn{2}{|c|}{ Autocorrelation } & \multicolumn{2}{|c|}{ Partial Correlation } & & $\mathrm{AC}$ & PAC & Q-Stat & Prob \\
\hline 1 & 1 & 1 & I & & -0.005 & -0.005 & 0.0024 & \\
\hline 1 & 1 & 1 & 1 & & 0.093 & 0.093 & 0.7466 & \\
\hline 1 & 1 & 1 & 1 & & -0.027 & -0.026 & 0.8079 & 0.668 \\
\hline 10 & 1 & 1 & 1 & & -0.075 & -0.085 & 1.3099 & 0.727 \\
\hline 吅 & 1 & 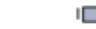 & 1 & & -0.151 & -0.150 & 3.3602 & 0.499 \\
\hline 10 & 1 & I [ & 1 & & -0.099 & -0.091 & 4.2416 & 0.515 \\
\hline 10 & 1 & 1 & 1 & & -0.076 & -0.057 & 4.7676 & 0.574 \\
\hline 믄 & 1 & ㄷ & 1 & & -0.223 & -0.233 & 9.4059 & 0.225 \\
\hline 1 & 1 & 1 & 1 & & -0.034 & -0.076 & 9.5141 & 0.301 \\
\hline 1 & ים & 1 & اط & 10 & 0.155 & 0.157 & 11.806 & 0.224 \\
\hline 1 & 1 & 1 & 1 & 11 & 0.052 & 0.023 & 12.070 & 0.280 \\
\hline 1 & 1 & 1 & 1 & 12 & 0.014 & -0.089 & 12.089 & 0.357 \\
\hline 1 & 1 & 1 & 1 & 13 & 0.026 & -0.067 & 12.158 & 0.433 \\
\hline 1 & 1 & 1 & 11 & 14 & 0.049 & 0.033 & 12.405 & 0.495 \\
\hline 1 & 11 & 1 & 61 & 15 & 0.049 & 0.078 & 12.648 & 0.554 \\
\hline 1 & ים & 1 & 51 & 16 & 0.112 & 0.088 & 13.950 & 0.529 \\
\hline 1 & 1 & 1 & 11 & 17 & 0.043 & 0.039 & 14.145 & 0.588 \\
\hline 1 & 1 & 1 & 1 & 18 & -0.053 & 0.012 & 14.446 & 0.635 \\
\hline 1 & 1 & I & 1 & 19 & 0.003 & 0.058 & 14,447 & 0.700 \\
\hline 1 & 1 & 1 & j & 20 & 0.034 & 0.058 & 14.573 & 0.749 \\
\hline 1 & 1 & I & 口 & 21 & 0.097 & 0.148 & 15.644 & 0.738 \\
\hline I & 1 & 1 & 1 & 22 & -0.115 & -0.057 & 17.158 & 0.701 \\
\hline 1 & 1 & 1 & b & 23 & 0.008 & 0.041 & 17.165 & 0.754 \\
\hline 1 & 1 & 1 & 3 & 24 & -0.041 & 0.060 & 17.363 & 0.791 \\
\hline 1 & 1 & । & 1 & 25 & -0.055 & -0.020 & 17.732 & 0.816 \\
\hline 1 & 1 & 1 & 1 & 26 & -0.039 & -0.071 & 17.916 & 0.846 \\
\hline 1 & ים & 1 & ין & 27 & 0.099 & 0.108 & 19.147 & 0.830 \\
\hline 1[ & 1 & 1 & 1 & 28 & -0.046 & 0.015 & 19.414 & 0.854 \\
\hline 1 & 1 & 1 & 1 & 29 & -0.019 & -0.016 & 19.459 & 0.883 \\
\hline 1 & 1 & I & 1 & 30 & -0.040 & -0.144 & 19.666 & 0.903 \\
\hline 1 & 1 & 1 & 1 & 31 & 0.007 & -0.083 & 19.672 & 0.925 \\
\hline 10 & 1 & 1 & 1 & 32 & -0.042 & -0.020 & 19.913 & 0.938 \\
\hline 1 & 1 & 1 & I & 33 & 0.026 & -0.006 & 20.008 & 0.951 \\
\hline 1 & 1 & 1 & I & 34 & 0.047 & -0.009 & 20.323 & 0.959 \\
\hline 1 & (1) & 1 & יוp & 35 & 0.105 & 0.117 & 21.928 & 0.945 \\
\hline 11 & 1 & 1 & [1 & 36 & -0.015 & -0.056 & 21.960 & 0.958 \\
\hline
\end{tabular}

Figure 6. Correlogram of the Second Difference LSATIS (LSALES) Series (DDLSATIS (DDLSALES))

When the correlogram of the LSATIS (LSALES) series with the second difference was examined, it was seen that there were no statistically significant autocorrelations, the permanent memory disappeared in the series and thus the series became stationary. The time path graph and the second difference given in Figure 3 are observed as an indicator of stationarity. The Akaike information criterion (AIC) and Schwarz information criterion (SIC) values, which are the indicators of the goodness of fit of the model, were found to be -1.284237 and -1.933681 , respectively, and the smaller values of these values than the other models were accepted as a sign of the fit of the model.

\subsection{Stage 4. Predicting}

By using the fitted regression model, predictions can be made for the next years. To evaluate the predictive performance of the model, the reported series and the real series can be plotted side by side. This graphic is given in Figure 7. 


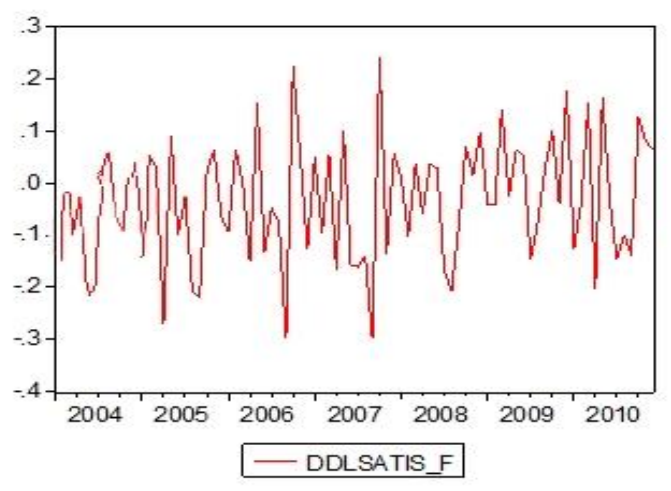

Figure 7. Prediction Series (DDLSATIS_F) (DDLSALES _F) vs. Real Series (DDLSATIS) (DDLSALES) Chart

As can be seen from Figure 7, preliminary reports can predict real series. It is possible to make a forecast for 2011 by using the model predicted in the 2 nd stage. The predicted value for January 2011 was found as;

$=1.43+2.23-0.03+1.04-2.03+0.01+0.33+0.29+0.24-0.33+0.17$ $=3.35$

on the model. However, since the natural $\log$ of the data was taken, reverse conversion has been made. In other words, the exponential value of 3.85 was obtained.

$=\exp (3,35)$

$=28.503$

In other words, the total personal loan sales projected for January 2011 is 28.503 (units). Considering this result, institutional resources should be planned, costing and profit target should be determined.

\section{Conclusions}

It is very difficult to decide the uncertain future. Every manager who is in the decision-making phase wants to know what will happen in the future and develop strategies accordingly. This need has led to the rapid development of econometric modeling. To analyze time series; has four main purposes: description, modeling, prediction, and control. To define the series, the descriptive statistics of the series should be calculated and plotted. The second purpose of analyzing time series is to find a suitable model of time series.

In the part of the time series application (virtual), the personal loan sales amounts of BetaBank INC. in 2004-2010 were analyzed. Before the stage of determining the appropriate model, in order not to cause spurious regression, stationarity analyzes were examined with the help of correlogram, time path graphs, and unit root tests. The natural logarithmic personal loan sales series was not stationary at its level and the first difference, when the second difference was taken, it has been observed that stability was achieved. The stationarity of the series with the second difference was shown again on the time path graph and hologram. After the stationarity was provided, the second difference was taken and the estimated model was formed. The fitness of the model was observed both on the correlogram and with the values of the Akaike information criterion (AIC) and Schwarz information criterion (SIC).

In terms of effectiveness, economics, and efficiency, the application of time series to sales is an approach that creates very rational results for businesses. It is the most effective method in resource planning and in parallel with determining the correct costing and consequently in profitability planning.

\section{References}

1. Akdi, Y. (2003). Time Series Analysis (Unit Roots and Co-integration). Ankara. Bıçaklar Kitabevi. p. 11. Available at: https://dspace.ankara.edu.tr/xmlui/bitstream/handle/20.50 $\underline{0.12575 / 41274 / \% C 4 \% B 0 S T 308 . p d f ? \text { sequence=1\&isAllo }}$ wed $=\mathrm{y}$

2. Box, G. P. E. \& Jenkins, G. M. (1976). Time Series Analysis: Forecasting and Control. San Francisco. Holden-Day.

3. Chatfield, Ch. (1995). The Analysis of Time Series: An Introduction. Newyork. Chapman and Hall.

4. Cochrane, J. H. (1997). Time Series for Macroeconomics and Finance. USA. Available at: http://econ.1se.ac.uk/staff/wdenhaan/teach/cochrane.pdf

5. Creel, M. (2005). Econometrics. Dept. Of Economics and Economic History. Universitat Autonoma de Barcelona. p. 130. https://doi.org/10.1007/s10614-005-6868-2

6. Creel, M. (2005). Econometrics. Barcelona. Dept. Of Economics and Economic History. Barcelona.

7. Damodar, N. G. (2004). Basic Econometrics. Newyork. The McGraw- Hill Companies. p. 23.

8. Delurgio, S.A. (1998). Forecasting Principles. and Applications. Newyork. Irwing McGraw-Hill Comp. p. 59-60.

9. Griffths, W.E., Hill, R. C., \& Judge, G.G. (1993). Learning and Practicing Econometrics. New York. John Wiley \& Sons. p. 642.

10. İslamoğlu, A.H. (2008). Marketing Management. İstanbul. Beta Publications. 
11. Johnston, J. \& Dinardo, J. (1997). Econometric Methods. New York. McGraw-Hill International Edit.

12. Kutlar, A. (2005). Applied Econometrics. Ankara. Nobel Yayın Dağıtım.

13. Maddala, G. S., \& Kim, I. M. (1998). Unit Root Cointegration and Structural Change. Cambridge. Cambridge University Press.

14. Maddala, G. S. (1992). Introduction to Econometrics. New York. Macmillan Publishing Company. Available at: https://jigjids.files.wordpress.com/2011/05/introductionto-econometric-2nd.pdf

15. Patterson, K. (2000). An Introduction to Applied Econometrics: A Time Series Approach. New York. Great Britain.

16. Pindyck, R. S. \& Rubinfeld, D.L. (1998). Singapore Econometric Models and Economic Forecasts. Irwin/ McGraw-Hill International Edit.

17. Pollock, D. S. G. (1999). A Handbook of Time Series Analysis Signal Processing and Dynamics. USA. Academic Press.

18. Pollock, D. S. G. (1999). A Handbook of Time Series Analysis Signal Processing and Dynamics. USA. Academic Press.

19. Serper, Ö. (1996). Applied Statistics 2. Istanbul. Filiz Publishing House. p. 289.

20. Sevüktekin M. \& Nargeleçekenler M. (2005). Time Series Analysis. Ankara. Nobel Yayın Dağıtım.

21. Sucu, Y. (2000). Foresight and Forecasting Methods in Management. Un-updated Book.

22. Tari, R. (2005). Econometrics. Istanbul. Avcı Offset. p. 429-430.

23. Tsay, R. S. (2004). Analysis of Financial Time Series. USA. John Wiley \& Sons. 